\title{
Cyber-Spatial Academic Networking for Energy (Oil, Natural Gas, Electricity) Development in Nigeria
}

\author{
Richard INGWE ${ }^{1,2}$ \\ ${ }^{1}$ Institute of Public Policy and Administration (IPPA), University of Calabar, Nigeria; \\ ${ }^{2}$ Centre for Research and Action on Developing Locales, Regions and Environment \\ (CRADLE), Calabar, Nigeria \\ ingwe.richard@gmail.com, cradle.africa@gmail.com
}

Philosophers of society/sociology recently espoused the concept of a new society and its new paradigm distinguished from the old that was based on industry and the energy forms that drove them since the industrial revolution. The new society which is driven by information and communications technologies (ICTs) has created the network society whereby cyberspatial (internet-based) platforms operate in leveraging previous and conventional interaction among researchers concerned with single subjects and/or multi-disciplinary research projects, exchanges of ideas, opinions, concerns/worries, viewpoints, project management, among other issues in the nexus of developing and applying academic knowledge. While most of those that are popularly used are of the universal (non-specific nationality or global) character, fairly country-specific (i.e. restricted membership or nationfocused) cyber-spatial platforms present opportunities for enhancing or optimizing the profit of academic interaction and exchanges that concentrate on challenges that are limited to one country but promote greater understanding among those academics involved compared to the rather universal cyber-spatial platforms. Here, we conceive and hypothetically theorize a cyber-spatial platform for enhancing interaction among Nigerian scholars and academics concerned with energy which has been driving industry. Examined in this article are: contexts of scholarship in Nigeria (tertiary educational institutions, research and knowledge needs for sustainable development; the network society as a suitable framework for theoretically framing the cyber-spatial platform; an exemplary multi-disciplinary approach for multidisciplinary petroleum oil, natural gas and energy concentrating on (or drawing from) the social sciences; management of the program; discussion and conclusion. The implications of this article for policy is that while the National Universities' Commission and the Federal Ministry of Education, TETFUND, (Tertiary Education Trust Fund), and related public agencies are responsible for funding and managing the proposed program, it is also the responsibility of individual tertiary educational institutions (TEIs) to demonstrate that the program presents opportunities for lifting it and its peers above the current miserable scenario whereby they all do not count in the list of the world's 500 leading universities.

Keywords: Cyber-Spatial/Internet, Platforms, Leveraging, Interaction, Researchers, Subjects/Multi-Disciplinary, Research, Program/Projects

\section{$\mathbf{1}^{1}$ Introduction}

Governments of post-independent Nigeria, faith organizations, and businesses have since the 1960s have viewed education system development as one of the most strategic socio-economic, science and technology development sectors. Evidence of this reflects in policies implemented by governments at two of three tiers of the federal system increasing establishment and management of tertiary educational institutions (TEIs). Nigerian governments at federal and states (comparable to provincial in many countries), and not yet local government areas/councils) have considered the opening of TEIs as a means of developing human capital to enhance their competitiveness and to increase their chances of improving social welfare and life quality. For a little longer than that period, the world have been in the throes of globalization and associated with that phenomenon has also 
been behavioral changes of a wide range of communities including entrepreneurs, academics and professionals affiliated to the TEIs regarding their rising adoption and use of information and communication technologies (ICTs) constitute the focal points of this article. The latter change concerned increasing adoption of ICTs in strengthening their networking for achieving their academic and professional goals. Some of the foregoing changes involve taking academics and professionalism memberships in ICTs-enabled platforms for specific disciplines or combinations of subjects e.g. Zotero (for specialists in the humanities), Mendeley (1.6 million users as at 2012, LinkedIn (professional networking), among others [19].

Recent reports about Nigeria's tertiary educational institutions (TEIs) have been concentrated on the need for producing human capital required for facilitating economic growth and socio-economic development in the country that has for too long been hailed as possessing potentials for becoming the "giant" of Africa and one of the leading economies of the world. In this regard, the need for examining and understanding the geographic distribution of the TEIs in Nigeria's six geo-political zones has been justified, undertaken and reported ([14]). Previously, the extent to which Nigeria's federal government facilitation of (in terms of shares) of web-based educational resources to secondary schools in the country's 36 states and Federal Capital Territory, FCT, was also explored ([15]) was also explored. The latter study highlighted the benefits that the internet as a component of the wider packages of facilities generically described as information and communications technologies (ICTs) as the justification for examining the way the government was considering (or otherwise) the principles of equity in offering such assistance to its various sub-national regional entities namely federal states.

\subsection{Inequality, social order and development in Nigeria}

Equity issues are important everywhere i.e. in every country appreciative of the way the principles of justice and fairness facilitates the creation of peace, order, harmonious coexistence of multiple cultural groups (societies) under one state (or nation that evolves from a sovereign state). It was pointed out that equity is more crucial in Nigeria because its gross inadequacy was responsible for the 30-month-long war waged by the secessionist and defunct Republic of Biafra in protest against what they declared as an unjust Federal Republic of Nigeria barely four years after the declaration of the latter in 1963 ([15]; [18]). The challenges also described as Nigeria's "national question" associated with conflicts among the multiplicity (about 350 or more) of cultural groups (ethnic nationalities) or civil societies forming Nigeria's federation are complex, complicated and frequently viewed as intractable by most analysts and observers ([9];[22]). Those challenges have received profuse attention by scholars concerned with the social sciences (sociology, political science, human geography, among others. The concentration on those socio-political and economic challenges has led to the current ignorance of the spectacular advances achieved in other areas such as human capital development technologies including the ICTs mentioned elsewhere in this paper.

Being the leading economy, most populous and one of the largest i.e. in geographic size as well as supplier of human capital to most countries in Africa and beyond makes the examination of cyber-spatial interaction by academics in oil, natural gas and energy in Nigeria urgent and imperative.

\subsection{Emerging academic programs concentrating on energy and economic growth challenges in Nigeria}

Participant observation and interviews revealed that a vital dynamic in Nigeria's TEI landscape is being expressed in the recent increase in graduate programs offering degrees and diplomas in energy generically 
i.e. including all sorts of energy resources. The latter would include fossil fuels both conventional and/or unconventional fossil fuels and/or geologically-mined forms that incorporate nuclear fuels to renewable energies, energy efficiency systems/technologies. Some of such programs include: Emerald Energy Institute (EEI) for Petroleum Economics, Policy and Strategic Studies University of Port Harcourt; energy and petroleum economics, professional Masters course in (Delta State University, Abraka) -both in the in the oilrich Niger Delta region; and the postgraduate course in energy economics, law and environmental studies in the University of Ibadan ([26]), south-west, among others that are presently unknown to us. These new programs pose implications for academic research, knowledge production and professionalism in energy. The postgraduates being (expected to be) produced from the foregoing programs are creating a pool of human capital constituting what we could describe as one generic community of energy specialists or subsets of more distinct communities of that area. As would be shortly demonstrated here, Manuel Castells theoretically and conceptually identified and commented upon such communities in his espousal of networking as a new or recent phenomenon in society.

\subsection{Energy (oil, natural gas and electricity) issues}

Challenges hampering the development of Nigeria's energy resources are being increasingly documented. For example, Richard Ingwe collaborated with colleagues ([14]) to recently identify some of the following issues. Owing the multiplicity of challenges facing Nigeria's energy sector, only a few of the many can be mentioned here. Despite abundant deposits of various energy sources, majority of Nigeria's population (projected at nearly 170 million) groan under the pains of inadequate clean energy products/services. Key problems regarding fossil fuels (petroleum oil, natural gas, Bitumen, etc.) deposits include government's care-free attitude towards exploration aimed at discovering and increasing available reserves of oil and gas, indifference to the Bitumen resources while importing same from Iran for road construction, among other uses. Scandalous corruption and mediocrity in economic management have dented Nigeria's energy sector records since the 1960s when the country gained political independence (1960). For nearly 30 years or thereabout, successive government regimes that have been dominated by dictators neither developed new oil refineries nor maintained the existing ones. This scenario was contrived criminally to facilitate perpetration of corruption in form of the scandalous oil subsidy. In 2012 alone, the media reported "The great $\$ 6.8$ (billion) oil scandal", ([25]). With a population of nearly 170 million people -only less than 50 per cent of whose mostly urbanites are connected to a rather poorly performing power grid, Nigerians is regarded as recipients of some of the lowest per capita electricity shares worldwide. Despite her endowment with very large and by and large poorly explored natural gas deposits (???), this resource being increasingly acclaimed for its distinctive potentials and operational contributions to socio-economic development in many countries of the world is yet to be developed for supplying energy for cooking and heating in Nigeria's numerous households ([14]).

\subsection{Objectives and organization}

The general objective of this article is to propose a cyber-spatial framework for facilitating scholarship in social scientific analyses of energy in Africa's most populous and largest economy (Nigeria). In the rest of this article, specific objectives i.e. aspects of the latter general objective this study shall be examined and organized in sections. After the introduction, we briefly examine the contexts of scholarship specifically the nature or size of TEIs in Nigeria (tertiary educational institutions, research and knowledge needs for sustainable development of the country's energy 
resources. Then we develop a suitable framework for theoretically framing the cyber-spatial platform for energy resources management for Nigeria. In doing so, we resort to Manuel Castells' proposition on the network society as deserving reconstruction for elucidating on the need for assembling academics into a network dedicated to energy research in Nigeria. We follow on by proposing an exemplary multi-disciplinary social sciences approach to petroleum oil and natural gas (concentration of the wider energy resources that require drawing upon the networking methods approach. We follow on by discussing the topic and concluding by summarizing the main points and stating the implications of this article for policy.

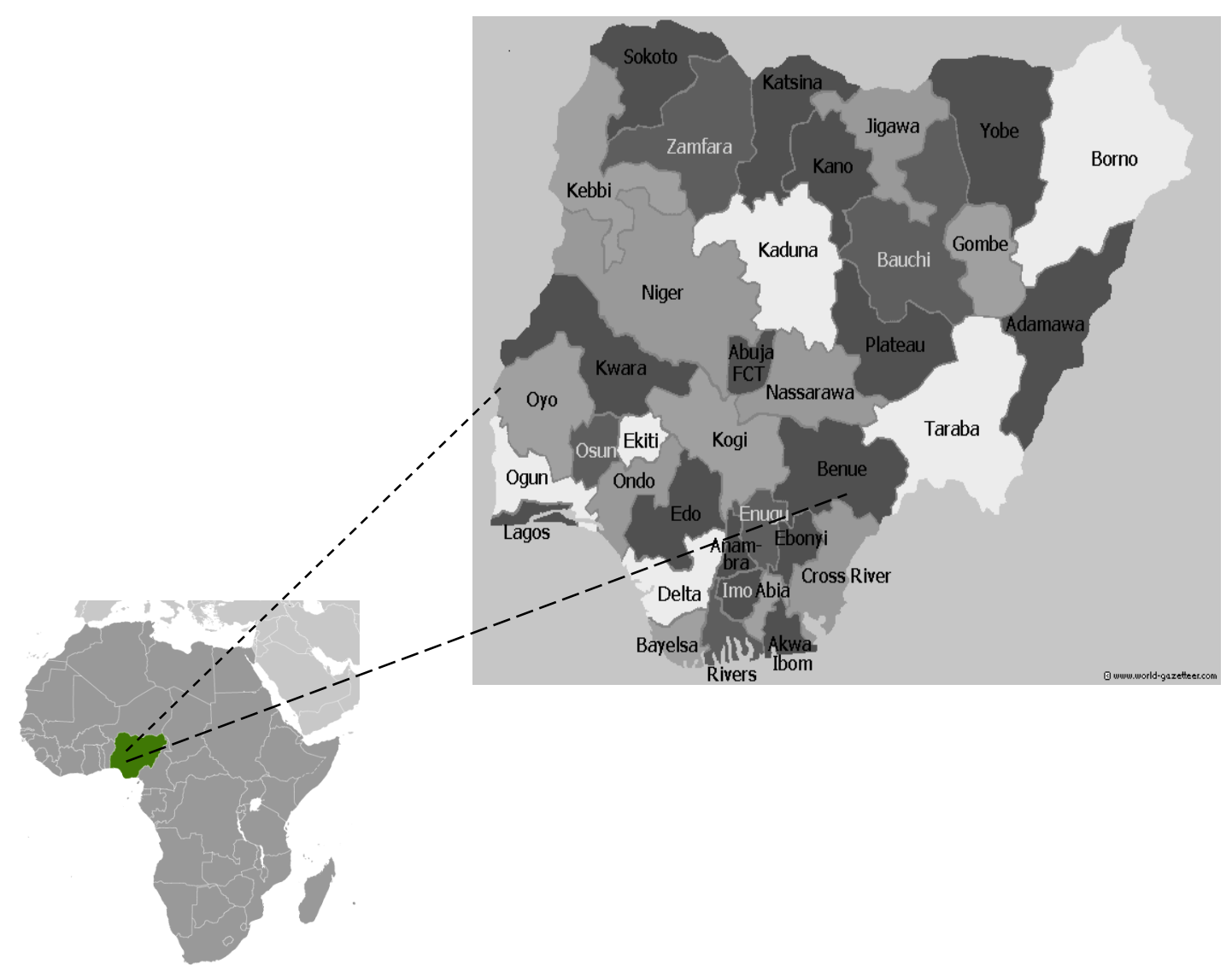

Fig. 1. Nigeria's 36 states and Federal Capital Territory projected from Africa [30], [31]

2 Specialized cyber-spatial platforms (ICTs) promoting interaction among scholars and academic research/knowledge dissemination

More recently, earlier ICTs (comprising internet or networked computers, hypertexts, among other components) have been reconstructed or transformed into increasingly specialized varieties. Rather focusing on mere exchanges of information of wide ranging forms or concerned with a mixture of everything, scholars (describing academic researchers and practitioners) concerned with specific subjects or disciplines or group of disciplines have employed creativity to push further the boundaries of networking that formed Manuel Castells thesis on the Network Society (Castells, 2000a, 1998, 1997, 1996). Some of such academic research networks are described in terms of their characteristics later in this article.

\subsection{Poor networking aggravating}




\section{challenges faced by under-performing Nigerian TEIs}

The competition aiming towards achieving higher levels of human capital resources (TEI graduates) by Nigeria's sub-national regions (geo-political zones, 36 states, 774 local government councils, L.G.As,) as well as individuals who have accumulated enormous wealth through neo-liberalizing violence has led to the proliferation of TEIs across the country. Since the report that the total number of TEIs (describing universities and Bachelors degree-awarding institutions in Nigeria) had reached 97 in late 2008/2009 ([14]; [17]), more of them (TEIs) have been established thereafter. The extent to which the existing TEIs have applied ICTs to leverage academic scholarship has remained poorly understood generally. Specifically, the level of deployment of the cyber-space as a medium of interaction by scholars concerned with identifying and interrogating development challenges hampering various aspects of development of Nigeria (economic growth, social harmony, political association, compromise making, environmental soundness, among others, remains unknown, by and large.

2.2. Why cyber-based platform for networking Nigeria's energy resource management academics: Justification

Recently, critiques of Nigeria's energy and energy resources are being documented. Some of these highlight the challenges concerning over-dependence of Nigeria's national economy and its three-tiered governments (federal, 36 states, FCT (Abuja), and 774 local government areas (councils) on earnings from crude oil export for financing socio-economic development ([14]; [13]) (1). Therefore, this centrality of energy resources to national income and the energy hunger in the country regarded as Africa's giant make a case for the need for more information and knowledge as requirements for enhancing development planning and management.

\section{The New CRADLE Initiative on Promoting Cyber-Spatial Academic Networking}

A logical response to the challenges of poor academic networking in Nigeria's energy sector is to create one or few but how shall such start? Who is reasonably concerned with the problem? How shall the project start and be designed and managed? The recent creation of the Centre for Multi-/Interdisciplinary Research in Energy and Energy Resources Assessment and Management at multiple (sub-)regional levels in Africa (CEMIDRERAM) by one of Africa's foremost sustainable development think tank, the Centre for Research and Action on Developing Locales, Regions and the Environment (CRADLE), arose from the institution's realization of the need for responding to the foregoing challenges faced by African economies regarding increasing energy demand locally and internationally and their implications for sustainable development. The latter justifies the multidisciplinary studies that cover various sectors: social, economic and environmental either separately or combinations of them. Therefore, some activities that shall be undertaken would include: outlining a curriculum for guiding the emerging research and education programs being designed to respond to challenges and needs of Africa.

The proposed initiative shall be managed through CRADLE's interdependence or collaboration with other governmental and non-government organizations. As much of the activities would include scholarship, publication of research-derived reports in numerous journals located in many regions of the world, the cyber-spatial platform will be handy for scholars from various TEIs in the region. CRADLE considers the foregoing as sufficient grounds for undertaking further philosophical and practices (work) including architectural designing and constructing the proposed cyber-spatial ICTs platform capable of assembling stakeholders for implementing the proposed program initiative. The think-tank also recognizes the need for related further work in proposing a 
framework for managing the cyber-spatial program. Arising from the foregoing outline, the general and specific objectives of this article were developed.

\section{Network Society Theory}

\subsection{The ways of globalization}

Insights into this theory by Geographer, Stephen Graham (see [11]: 498) suggest that it is underpinned by ICTs that represent the central instruments for driving multidimensional transformations associated with globalization. The latter involves acceleration of shifts in societies of globalization in terms of economic, cultural, and social sectorial flows. Its origin is credited to Manuel Castells, whose two professorships (in urban and city planning and another in sociology) strategically placed him to gain multi-disciplinary insights into the foregoing involved transformations. The articulation of this theory was espoused through a trilogy of publications over three years of the late 1990s. In that trilogy, Castells explores the increasing phenomenal employment of networking in various communities (entrepreneurs, phenomenal processes of social exclusion world-wide, dynamics in the characteristics of time and space, creation of identity and sovereign state and changes in social structures underlying the new society that has been created. Genetic engineering is a component of the new technological paradigm concerned with biological information i.e. concentrating on biological life information ([4], [5], [6], [7]).

\subsection{Energy and information technologies compared}

Castells subscribes to Claude Fisher's definition (1992), which rather than viewing technology as a factor affecting society exogenously, sees it as material culture that is a socially embedded process. Specifically, electronically organized information networks created by ICTs constitute material instruments of social transformation that facilitate the formation of new kinds of social organization and interaction. Castells likens this way of transforming communities in society by ICTs to the manner in which energy facilitated industry during and after the revolution of this wave of societal transformation in the $17^{\text {th }}$ century (Castells, 2000: 693-4).

\subsection{ICTs-dominated spaces of acceleration and globalization}

The central theme of the theory is the proposition of distinction between two spaces: the first is globalized, rapid i.e. accelerated, dominantly driven by ICTs.

4.4. Geographical spaces of individual and group identity

The second space is characterized by geographic confinement of sources of group identity and individuals (Graham, in: [11]: 498). Networks are old phenomena. Therefore, there is need to ask how have ICTs transformed old networking to merit this attention?

\subsection{Distinctive value added by ICTs to networking}

Castells' encouragement of the sociology of the network society explains that electronic communication has added value to networking by facilitating old networks' capacity for coordination of purposes, decision making, decentralization, modified tasks implementation. This means that both performance and flexibility can be achieved simultaneously. Centralized (hierarchical) organization of networks has been eliminated through increasing competition among networks whose performance have become superior within specific activity areas. Networks (in social practice) serve to redefine social structure i.e. human organizational forms of meaningful human relationships as people engage in production and/or consumption, experience and power shaped by culture ([3], [4]).

\subsection{Relevance of the theory to energy specialists}

Despite the rather brevity of this review of an important theory, comments on its value or suitability are necessary. One of many possible points on the relevance of the theory 
to this present task is sufficient. As a means of elucidating the creation of the proposed cyber-spatial platform for networking by energy specialists after the theory's elaboration in Castells' trilogy, the success gained from his drawing from the tested proposition to demonstrate the need for networking for sociologists ([3]) points towards its relevance for many other specialists and academic disciplines and fields.

\section{Methods, Data/Sources}

We used the hypothetic-deductive methodology universally accepted by the general scientific community is suitable for implementing this study including presentation of this article.

\subsection{Descriptive case study method}

Arising from the latter (methodology), descriptive case study -as an aspect of the overall methodology- presented a specific and suitable method for implementing this study. Many researchers' reporting their previous academic investigations involving the application of descriptive case study method(s) whether applied separately or jointly) have confirmed their suitability for guiding research focusing on understanding relatively less popular research projects themes. This justifies the application of descriptive case study method here because it provides a means of elucidating similar scenarios (cyber-spatial platforms for academic research and related networking) in Nigeria. Additionally, description has reportedly proven to be reliable in the service of manifold academic projects of the kind presently reported here. Therefore, our adoption of the case study approach is justified by the fact that by examining cyberspatial platforms for academic research and related networking, our objective of producing knowledge capable of informing our insights into the challenges faced by similar academic research communities opportunities of obtaining first-hand knowledge of the area/field is both enhanced and expanded ([21]).

\subsection{Data/sources}

We obtained and used data/information from primary and secondary sources. Primary data gathering was enabled by our memberships, interview and observation of academic networks available over the internet (see some examples stated in this paper). Beyond the latter, the networks constituted secondary sources that are open or available for confirmation by the reading public. The web facilitated our desk research for developing the theoretical and conceptual framework for this study/paper.

\section{Academic Networks and Societies}

Kathrine Mangan ([19]) hails academic networks that have proliferated since the inception of this phenomenon despite earlier doubts regarding their value. She lists a number of their examples to include:

\subsection{ResearchGate}

This is one of the cyber-spatial (online) networks of scholars and academics who are attracted to websites that are designed and dedicated towards promoting: assemblages of academic research publications (peerreviewed journal articles, books, databases; academic jobs (i.e. advertisements of vacancies; scholarly exchanges i.e. restricted requests for articles that are restricted by their publishers from their individual authors, etc.); scholarly profiling i.e. specification of personal information concerning academic and professional specializations, academic research interests, scholarly achievements e.g. grants won, scholarships, laurels won, personal scholarly following (nomenclature and related personal descriptors or information of other scholars attracted to the works of individual academic; multi-mode or multi-entity memberships i.e. individual scholars, academic organizations, TEIs, are allowed to its membership; Penetrating reporting system i.e. various approaches to highlighting geographies and temporalities of scholarly queries, searches for articles, data, by country of origin of academics in-need of publications, responses or otherwise to 
queries; Grading of academic interaction i.e. scoring of the extent to which individual scholars have published, presented articles in various for a (conferences, publics, etc.); among others. The foregoing or latter description approximately fit one of such cyber-spatial scholarly platforms (Research gate) that the authors hold memberships in.

It was founded in 2008 by a computer scientist and virologist, Ijad Mardish, its base was moved from Boston to Berlin a year afterwards. Contribution from scientists led to its rapid rise in users from 25,000 in 2009 to greater than a million in 2011 and 2.6 million in 2013. By 4 June 2013, it attracted series $\mathrm{C}$ financing from investors including Bill Gates to the tune of US\$ 34 million (Wikipedia, 2014).

\subsection{Academic edu}

Another cyber-spatial platform, "Academic edu" (2014) facilitates searches focusing on "people, research interests, Universities", monitoring of the impacts of articles uploaded by members, specifically presents icons directing its members to: ask questions, updating research articles by either providing most current and previous papers, uploading digital files of same or both, and posting related matters including: opinions, viewpoints, feelings, observations, scholarships, jobs. Additionally, this presents related platforms for enhancing the gathering of educational data/information through inter-connection with other online networks that its members hold memberships but that are not necessarily devoted to academics but focus networking aimed at socializing. Some examples of the latter include: Facebook, LinkedIn, Twitter, blog, among others (Academic.edu.net 2014).

\subsubsection{Origin, justification characteristics of Academic.edu.net}

and

Founded by Richard Price after completing his doctorate degree in philosophy at the University of Oxford in 2007 before relocating to San Francisco later, then raised $\$ 600,000$ from Spark Ventures, Brent Hoberman, and others to launch what has become one of the most successful academic interaction platforms in September 2008 (Wikipedia, 2014), Academia.edu is a site for sharing research papers and more. Price's consideration preparatory to founding Academic-edu.net was that "With networks like Twitter and Facebook, information whizzes around at laser speed". He adds that "whereas in science, and research in general, the average time lag is a year before a paper gets in a journal and is distributed to the rest of the world". Comparing the lag in print dissemination of knowledge to those enhanced by ICTs, or the Web, Price acknowledges the instantaneous distribution of the latter. He states that "When you read a paper and want to comment, you'll be able to respond immediately"..."The conversation will take minutes and hours instead of months and years.". Funding of the site was enabled by its proposal's attraction of "\$6.7million in seed capital from a variety of investors. Free subscription or signs up unto the site was estimated at 3,500 new users (scholars/academics) per day around 2012, three million unique visitors per month (Mangan's interview with Price, 2012). Launched in September 2008, its following as at 2014 had accelerated to registered membership size of eight million, (Wikipedia, 2014). Single subject scholarship promoting sites have employed approaches similar to Academic.edu.net for years. A good example of some scientific fields that have created and/or gained from such services is the arXiv preprint service, which has offered such features to researchers in physics since 1991 [19].

Technology monitors (Tech Crunch) have reportedly described Academia.edu in very good terms as a platform providing academics: a "powerful, efficient system for distributing their research; enabling researchers to monitoring readership size of "their articles by applying specialized analytics tools", and a platform that performs very well in interfacing with Google search in terms of producing results.". Academia.edu is regarded as reflecting a combination of social networking norms and 
academic norms ([27], [28]).

\section{Conclusion}

ICTs' (especially internet's advent in the past few decades have redefined many cultures including networks of academics by opening new vistas for tasks handling, organization of work, among others. In Nigeria, where most of national and sub-national revenue has over-depended on crude oil and natural gas export, re-organization of networks of academics specializing in energy represents a means of guaranteeing the production of information/knowledge required for strengthening economic management by leveraging work in the priority economic sector. This paper has articulated a suitable theoretic-conceptual framework and identified issues relevant to further design and construction of a cyber-spatial platform for interaction by academics researching, discussing and activating issues in Nigeria's energy sector could be proposed. Further work should move the latter aspiration to the next stages.

\section{Notes}

1. Earnings from crude oil export contributes to over 90 per cent of Nigeria's total revenue. The sudden switch from an agricultural sector-centric sub-national regional-based fiscal regime to petroleum oil with natural gas waste-flaring in post-oil Nigerian economy defines the country's version of petro-capitalism (resource curse).

2. The multi-disciplinary social scientific studies refer to especial examinations of the various disciplinary bifurcations of fossil fuels with natural resources petroleum oil/gas, bitumen, etc., other energies i.e. electric power with economics, political science, human geography, sociology, psychology, and management sciences, law, among others.

\section{References}

[1] Academic edu. 2014. Accessed 12 July 2014 from: "Search people, research interests, Universities". https://www.academia.edu/?notification_ code $=$ aJnTVJef.

[2] "Academia.edu - $\$ 4.5 \mathrm{M}$ in Funding, $3 \mathrm{M}$ Unique Monthly Visitors - Can They Change Science Publication?". Singularity Hub. 2011-12-11. Retrieved 2012-02-22.

[3] M. Castells, 2000a. Towards a sociology of the network society. Comparative Sociology, 29(5): 693-699. September.

[4] M. Castells, 2000b [1996]. The information age: economy, society, and culture. 3 vols. 2 ed. Malden \& Oxford: Blackwell.

[5] M. Castells, 1998. End of millennium. Volume 3 of The information age: economy, society, culture. Oxford: Blackwell.

[6] M. Castells, 1997. The power of identity. Volume 2 of The information age: economy, society, culture. Oxford: Blackwell.

[7] M. Castells, 1996. The rise of the network society. Volume 1 of The information age: economy, society, culture. Oxford: Blackwell.

[8] Centre for Research and Action on Developing Locales, Regions and the Environment (CRADLE). Brochure. Calabar: CRADLE.

[9] IA Eteng, 2008. "Ethnicity, Ethno-Class Relations and Crisis of Nigeria's Enduring 'National Question' and Political Instability", In: D. Oni, S. Gupta, T Omoniyi, E Adegbija, \& S Awoniusi (eds.) Nigeria and Globalisation: Discourses on Identity Politics and Social Conflict: 37-81.

[10] G. M. Rolando and N. F. Hannah, 2013. "Provision of online reference through ResearchGate", Journal of the Medical Library Association, 101.4.

[11] D. Gregory, R. Johnson, G. Pratt, M. Watts, \& S. Whatmore (Eds.). 2009. The Dictionary of Human Geography. Chicester: Wiley-Blackwell.

[12] R. Ingwe, I. Anwunah, E. Ojiegbu, O. Martins, 2014. Energy and energy resources in Nigeria (Unpublished term paper submitted to Professor O. Iledare, Emerald Energy Institute, University of 
Port Harcourt, Nigeria).

[13] R. Ingwe, 2014. Economic-financial management performance of Nigeria's sub-national regions (states) in the context of Petro-capitalism in the 2000s: Regionalising based on Nigeria's six geopolitical zones (Unpublished paper on file at CRADLE, also submitted for publication by a peer reviewed journal).

[14] R. Ingwe, C. C. Ikeji and U. Ugwu, 2011: Sub-national regional development and degree-awarding tertiary educational institutions in Nigeria: Descriptive, geodemographic and geospatial analyses. In: Journal of Urban and Regional Analysis (JURA), Vol. 3, No. 1, pp. 77-103.

[15] R. Ingwe, J.E. Otu, S. Agi, I.E. Eja \& J.K. Ukwayi, 2008, Federal Government Assistance for Web-based Secondary Education under Poor Socio-economic Development Conditions in Nigeria: Geodemographic and Qualitative Analyses, in: Journal of Geography and Regional Planning, Vol. 1 (4), pp.072084.

[16] A.J. Isangedighi, M.T. Joshua, A.E. Asim \& E.E. Ekuri, 2004. Fundamentals of Research and Statistics in Education and Social Sciences. Calabar: University of Calabar Press, 308.

[17] JAMB (Joint Admission and Matriculations Board). 2008/9. Universities Matriculations Examinations and Direct Entry (UME/DE) Guidelines for admissions into first degree courses in Nigerian universities and other degreeawarding institutions. Abuja: JAMB.

[18] O.O. Ladipo, 1989. Nigerian economic development and international externalities (Inaugural lectures series, 79), Ile-Ife: Obafemi Awolowo University Press Ltd.

[19] K. Mangan, 2012. Social Networks for Academics Proliferate, Despite Some Doubts, In: The Chronicle of Higher Education. Accessed 12 July 2014 from: http://chronicle.com/article/Social-
Networks-for-Academics/131726/.

[20] ResearchGate. 2014. Scholars membership network. Accessed 18 July 2014 from: https://mail.google.com/mail/u/0/h/ytpbra f9n0ny/? \&v=c\&th=1474494d124a606c.

[21] M.B. Ogunniyi, 1992. Understanding Research in the Social Sciences. Ibadan: University Press PLC.

[22] O. Otite, 1990. Ethnic Pluralism and Ethnicity in Nigeria. Ibadan: Shaneson CI Ltd.

[23] S. Oyovbaire, 2000. Civil society and democracy: Theoretical Perspectives: In: Okon E. Uya (ed.) Civil society and the consolidation of democracy in Nigeria (Proceedings of the IPPA Second International Seminar, 25 and 26 May, 2000, University of Calabar. Calabar: CATS Publishers: 13-24.

[24] R. Stankiewicz, 1986. Academics and Entrepreneurs: Developing UniversityIndustry Relations. London: Frances Pinter (Publishers).

[25] "The great $\$ 6.8$ (billion) oil scandal", The Africa Report (Paris), 6/2012: 36-40. Accessed 20 July 2012 at: www.theafricareport.com.

[26] University of Ibadan. 2014. Postgraduate courses in the Centre for Petroleum, Energy Economics, and Law (CPEEL). July. Accessed 15 ${ }^{\text {th }}$ July, 2014 from:http://cpeel.ui.edu.ng/?p=admission.

[27] Wikipedia. 2014a. citing Academia.edu CrunchBase Profile". Crunchbase.com. Retrieved 2012-02-22.

[28] Wikipedia. 2014b. Academic.edu. Retrieved 12 July 2014 from: http://wikipedia.org/wiki/Academia.edu.

[29] Wikipedia. 2014c. Research Gate. Retrieved 18 July 2014 from: http://wikipedia.org/wiki/ResearchGate

[30] http://www.worldofcultures.org/1024/ africa/AfricaMaps/nigeria.gif

[31] http://www.world-gazatteer.com. 


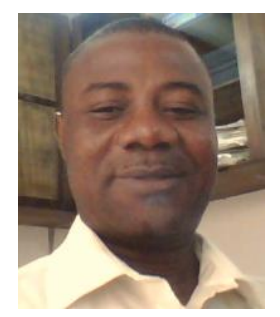

Richard INGWE research professes multiple geographies (economic, sociopolitical, physical aspects of space/society/environment), urban and regional development planning/management, and sustainable development management. I've written over 120 research papers -nearly 50 of them published/accepted for publication in peer-reviewed journals and another 24 of my articles are published in technical reports and books. I'm researching petroleum economics, policy and strategy in Emerald Energy Institute, University of Port Harcourt, a post-graduate of multiple fields including: spatial/regional development planning/management (University of Dortmund, Germany); remote sensing/geoinformation sciences of the UN-Regional Centre for Aerospace Surveys/RECTAS; a certificated geo-demographer/geo-information specialist. I've managed research programmes, set research agenda for Africa's leading sustainable development think tank (Centre for Research and Action on Developing Locales, Regions and the Environment, (CRADLE) and the Institute of Public Policy and Administration (IPPA), University of Calabar (Nigeria). 